\title{
NQO1 expression correlates inversely with NF $\kappa$ B activation in human breast cancer
}

\author{
Maral Jamshidi • Jirina Bartkova • Dario Greco • Johanna Tommiska • \\ Rainer Fagerholm · Kristiina Aittomäki · Johanna Mattson · Kenneth Villman • \\ Radek Vrtel · Jiri Lukas · Päivi Heikkilä · Carl Blomqvist · Jiri Bartek • \\ Heli Nevanlinna
}

Received: 9 May 2011 / Accepted: 3 June 2011/Published online: 25 June 2011

(C) Springer Science+Business Media, LLC. 2011

\begin{abstract}
NQO1 participates in cellular defense against oxidative stress and regulates apoptosis via p53- and $\mathrm{NF} \kappa \mathrm{B}$-mediated pathways. We have previously found that homozygous missense variant NQO1*2 (rs1800566) predicts poor survival among breast cancer patients, particularly after anthracycline-based adjuvant chemotherapy. Here, we investigated $\mathrm{NQO} 1$ and $\mathrm{NF} \kappa \mathrm{B}$ protein expression and global gene expression profiles in breast tumors with correlation to tumor characteristics and survival after adjuvant chemotherapy. We used immunohistochemical analysis of tissue microarrays to study $\mathrm{NQO} 1$ and $\mathrm{NF} \kappa \mathrm{B}$ expression in two series of tumors: 1000 breast tumors unselected for treatment and 113 from a clinical trial comparing chemotherapy regimens after anthracycline
\end{abstract}

Electronic supplementary material The online version of this article (doi:10.1007/s10549-011-1629-5) contains supplementary material, which is available to authorized users.

M. Jamshidi · D. Greco · J. Tommiska · R. Fagerholm ·

H. Nevanlinna $(\bowtie)$

Department of Obstetrics and Gynecology, Biomedicum

Helsinki, Helsinki University Central Hospital, P.O. Box 700, 00029 Helsinki, Finland

e-mail: heli.nevanlinna@hus.fi

J. Bartkova $\cdot$ J. Lukas $\cdot$ J. Bartek $(\bowtie)$

Institute of Cancer Biology and Centre for Genotoxic Stress

Research, Danish Cancer Society, Strandboulevarden 49,

2100 Copenhagen, Denmark

e-mail: jb@cancer.fi

J. Tommiska

Institute of Biomedicine, Physiology, University of Helsinki,

Helsinki, Finland

K. Aittomäki

Department of Clinical Genetics, Helsinki University Central

Hospital, Helsinki, Finland treatment in advanced breast cancer. We used gene expression arrays to define genes co-expressed with NQO1 and $\mathrm{NF} \kappa \mathrm{B}$. NQO1 and nuclear $\mathrm{NF} \kappa \mathrm{B}$ were expressed in $83 \%$ and $11 \%$ of breast tumors, and correlated inversely $(P=0.012)$. NQO1 protein expression was associated with estrogen receptor $(\mathrm{ER})$ expression $(P=0.011)$, whereas $34.5 \%$ of $\mathrm{NF} \kappa \mathrm{B}$-nuclear/activated tumors were $\mathrm{ER}$ negative $(P=0.001)$. NQO1 protein expression and $\mathrm{NF} \kappa \mathrm{B}$ activation showed only trends, but no statistical significance for patient survival or outcome after anthracycline treatment. Gene expression analysis highlighted 193 genes that significantly correlated with both NQO1 and NF $\kappa \mathrm{B}$ in opposite directions, consistent with the expression patterns of the two proteins. Inverse correlation was found with genes related to oxidation/reduction, lipid biosynthesis and steroid metabolism, immune response, lymphocyte activation, Jak-STAT signaling and apoptosis. The inverse relationship between $\mathrm{NQO} 1$ protein expression and $\mathrm{NF} \kappa \mathrm{B}$

J. Mattson - C. Blomqvist

Department of Oncology, Helsinki University Central Hospital, Helsinki, Finland

K. Villman

Department of Oncology, Örebro University Hospital,

Örebro, Sweden

R. Vrtel · J. Bartek

Institute of Molecular and Translational Medicine, and Laboratory of Genome Integrity, Palacky University, Olomouc, Czech Republic

P. Heikkilä

Department of Pathology, Helsinki University Central Hospital, Helsinki, Finland 
activation, underlined also by inverse patterns of association with ER and gene expression profiles of tumors, suggests that $\mathrm{NQO} 1-\mathrm{NF} \kappa \mathrm{B}$ interaction in breast cancer is different from several other tissue types, possibly due to estrogen receptor signaling in breast cancer. Neither NQO1 nor $\mathrm{NF} \kappa \mathrm{B}$ protein expression appear as significant prognostic or predictive markers in breast cancer.

Keywords Breast cancer $\cdot \mathrm{NQO} 1 \cdot \mathrm{NF} \kappa \mathrm{B} \cdot$

Chemotherapy $\cdot$ Metastasis

\section{Introduction}

To improve individualized therapy, novel predictive markers are needed that identify patients with expected poor breast cancer outcome or patients who benefit most from a given treatment. We have recently shown that $\mathrm{NAD}(\mathrm{P}) \mathrm{H}$ : quinone oxidoreductase 1 homozygous genotype, NQO1*2, predicts poor survival among breast cancer patients, particularly after anthracycline-based adjuvant chemotherapy and in p53-aberrant tumors [1]. This functionally important common missense variant (rs1800566, c.558C $>$ T) destabilizes NQO1 and cells homozygous for the mutant allele are deficient in NQO1 activity. Whereas the wild-type NQO1 protein is stable in cells, the variant form of NQO1 is rapidly turned over via ubiquitination followed by proteasomal degradation [2-4]. NQO1 is expressed in various normal tissues including breast and elevated NQO1 expression was reported for breast, ovarian, pancreatic, thyroid, adrenal, colon, and corneal cancer [5-7].

NQO1 has multiple functions including protection against cytotoxicity and carcinogenicity of quinones and oxidative stress by catalyzing reduction and detoxification of quinone substrates $[8,9]$. NQO1 plays a role in regulation of cell survival versus apoptosis through its interaction with $\mathrm{p} 53$ and links with the $\mathrm{NF} \kappa \mathrm{B}$ pathway. NQO1 regulates the stability of $\mathrm{p} 53$, protecting it from $20 \mathrm{~S}$ proteasomal degradation. Active NQO1 increases the basal level and induction of p53, potentiating apoptosis especially in response to oxidative stress [10-12]. Its role in $\mathrm{NF} \kappa \mathrm{B}$ signalling is less clear. $\mathrm{NF} \kappa \mathrm{B}$ is a transcriptional regulator of NQO1, and NQO1 in turn regulates $\mathrm{NF} \kappa \mathrm{B}$ activation under certain conditions $[13,14]$. While $\mathrm{NF} \kappa \mathrm{B}$ activation usually triggers cellular pro-survival, pro-proliferation responses, it can also lead to cell death [15]. The role of NQO1 in this context also varies from antiapoptotic to proapoptotic, possibly depending on cell type and/or microenvironmental factors. In mouse models the loss of NQO1 is accompanied by impaired function of $\mathrm{NF} \kappa \mathrm{B}$, as $\mathrm{TNF}-\alpha$ is unable to activate $\mathrm{NF} \kappa \mathrm{B}$ in NQO1-deficient mice. Moreover, it has been demonstrated that treating NQO1-wild-type cells with dicoumarol, an inhibitor of
NQO1, abolishes TNF-induced $\mathrm{NF} \kappa \mathrm{B}$ activation $[13,16]$. We have also previously shown that NQO1 enhances TNF-induced apoptosis in human breast tumors [1], and a similar effect has been reported in breast carcinoma cells in vitro [17].

Nuclearfactor $\mathrm{kB}(\mathrm{NF} \kappa \mathrm{B})$ is a transcription factor that is mostly cytoplasmic and translocates to nucleus upon activation [18]. While the basal level of active NF $\kappa$ B is minimal in most cell types, the constitutive activation of $\mathrm{NF} \kappa \mathrm{B}$ has been observed in various tumor types including human breast cancer [19]. Emerging evidence indicates the involvement of constitutively active $\mathrm{NF} \kappa \mathrm{B}$ in proliferation, angiogenesis, cell survival, metastasis, and apoptosis. For instance, in breast cancer cells, particularly with negative estrogen receptor status, $\mathrm{NF} \kappa \mathrm{B}$ activity is constitutive and thought to protect tumor cells against apoptosis [20, 21]. Indeed, elevated $\mathrm{NF} \kappa \mathrm{B}$ expression was suggested to associate with cancer cell resistance to radiation [22] and anthracycline-based chemotherapy [23]. Furthermore, while anthracycline-based treatment (doxorubicin) reportedly activates $\mathrm{NF} \kappa \mathrm{B}$ in cancer cells [24], $\mathrm{NF} \kappa \mathrm{B}$ signaling induced by doxorubicin was also implicated in reduced expression of $\mathrm{NF} \kappa \mathrm{B}$-dependent genes in cancer cells due to its instability in vivo [25].

Here, we analyzed NQO1 protein expression and $\mathrm{NF} \kappa \mathrm{B}$ nuclear localization in an extensive series of sporadic and familial non-BRCA1/2 breast tumors and in a second series of primary breast tumors from patients in clinical trials comparing chemotherapy regimens after anthracycline treatment in advanced breast cancer, to investigate their correlation to clinical characteristics and breast cancer survival. Additionally, we used gene expression profiling to explore genes correlating with $\mathrm{NQO} 1$ and $\mathrm{NF} \kappa \mathrm{B}$ expression in human breast tumors.

\section{Patients and methods}

NQO1 and $\mathrm{NF} \kappa \mathrm{B}$ protein expression was analyzed in two series of invasive breast tumors. The first series included 884 tumors from unselected breast cancer patients and additional 542 familial cases. The unselected cases were ascertained at the Department of Oncology, Helsinki University Central Hospital, during the years 1997-1998 and 2000 as previously described [26, 27]. The additional 542 familial breast cancer cases were collected by a systematic screening at the Department of Oncology, Helsinki University Central Hospital or were ascertained through genetic counseling at the Department of Clinical Genetics. The total number of 1,238 invasive breast carcinomas were available for TMA as described [28], including 423 from cases without familial background of breast cancer and 815 from patients with family history. Of the familial cases, 
480 patients have strong family history of breast cancer (three or more first or second degree relatives with breast or ovarian cancer in the family, including the proband), and 335 had two affected first-degree relatives (including the proband). BRCA1 and BRCA2 mutations had been excluded from the familial patient series as described [29-31].

Clinicopathological information on patients' characteristics, tumor size, nodal status, distant metastasis, estrogen and progesterone receptor status was collected from the pathology reports. A breast cancer pathologist (P.H.) re-reviewed all tumors for histological diagnosis and grade using the Scarff-Bloom-Richardson method, modified by Elston and Ellis [32]. Information on the tumor marker data used (p53, HER2, and ki-67) [33-36] can be found in the Supplementary Note.

Information on adjuvant treatment and distant metastases during the follow-up was collected from the patient records. The information on death due to breast cancer or other reason was obtained from the Finnish Cancer Registry. Survival was calculated as 10 years overall survival (10 years OS): the time from diagnosis to the date of death due to breast cancer or other reasons, and as 5 years survival from metastasis to death: the time from distant metastasis to the date of death. Detailed information on the survival analysis can be found in the Supplementary Note.

The second series consists of 283 breast cancer patients with distant metastasis who participated in a randomized multicenter trial comparing taxotere (docetaxel) with methotrexate-fluorouracil (MF) after failure of anthracycline treatment in advanced breast cancer [37]. From these, 113 primary breast tumors on tissue microarrays (TMA) were available for our analysis. TMAs were prepared as described [38]. Response evaluation was performed according to the WHO recommendations [39]. Treatment response, time to progression (TTP), and overall survival (OS) from start of anthracycline treatment preceding randomization were analyzed. For statistical analysis, clinical response was divided into two categories: response (complete or partial) and non-response (no change and progression). Overall survival (AOS) was calculated from the start of anthracycline treatment until death. Time to progression (ATTP) was calculated from the start of anthracycline treatment till disease progression. AOS and ATTP data were available for 70 and 55 tumors stained for NQO1 and $\mathrm{NF} \kappa \mathrm{B}$, respectively. Time to progression (TTP) on methotrexate-5-FU or docetaxel was measured from the date of randomization till disease progression. Of the 113 studied tumors, all were available and scored for NQO1, while 80 were available and scored for $\mathrm{NF} \kappa \mathrm{B}$.

This study was done with patients' informed consent and permissions from the Ethics Committee of the Helsinki University Central Hospital and the Ministry of Social
Affairs and Health in Finland. The study was performed according to reporting recommendations for tumor marker prognostic study (REMARK) [40].

Immunohistochemistry

TMAs were constructed as described [28], including four cores (diameter $0.6 \mathrm{~mm}$ ) of the most representative area from each formalin-fixed and paraffin-embedded breast cancer specimen. For NQO1 analysis, TMA slides were stained with mouse monoclonal anti-human NQO1-antibody (Santa Cruz, diluted 1:500). For NF $\kappa$ B analysis, the TMAs were stained with rabbit monoclonal anti-human $\mathrm{NF} \kappa \mathrm{B}$ (ABCAM, diluted 1:1000). The secondary reagents were from Vector Laboratories (Burlingame, USA), and the chromogenic substrate enhancement step was performed as described, without nuclear counterstaining [41]. As only $0-1 \%$ of normal breast tissue or tumor cells were immunohistochemically positive for NQO1 in individuals with homozygous c.558C $>\mathrm{T}$ variant, we generally considered the breast tumors positive for NQO1 when $2 \%$ or more of the cancer cells were positive for NQO1 staining and negative when fewer than $2 \%$ were stained. For $\mathrm{NF} \kappa \mathrm{B}$ immunohistochemistry, a 5\% cut-off was reported for nuclear staining in prostate cancer [42]. Consistently, we observed only rare nuclear positivity in normal or benign breast tissue $(n=30)$, and therefore we also considered $\mathrm{NF} \kappa \mathrm{B}$ as positive/activated in the breast carcinomas when $5 \%$ or more cancer cells showed nuclear staining and negative when fewer than 5\% cells showed nuclear signal, or only cytoplasmic staining for $\mathrm{NF} \kappa \mathrm{B}$.

\section{Microarray data analysis}

Total RNA was extracted from 183 primary breast tumors. The samples were processed and hybridized to Illumina HumanHT-12 v3 Expression BeadChips, containing 24660 Entrez Gene entities, according to the manufacturer recommendations (http://www.illumina.com).

Microarray raw data were imported into R (http:// cran.r-project.org) and processed by the methods included in the BioConductor facilities [43]. After quality control [44], the data were normalized using the quantile method [45] and the gene expression matrix was obtained by averaging the probes mapping to the same Entrez Gene IDs [46]. The Pearson's correlation of each gene expression profile with the expression of $N Q O 1$ and $N F \kappa B I$ was, respectively, calculated and the nominal $P$ values were estimated. The genes with correlation $P$ value $<0.01$ after Benjamini-Hochberg post hoc correction were further analyzed [47]. Functional annotation was performed on the $N Q O 1$-correlated and the $N F \kappa B 1$-correlated gene lists using the DAVID annotation tools [48]. The categories 
with Fisher's exact test $P$ value $<0.05$ were considered to be significantly enriched.

\section{Statistics}

Statistical analyses were conducted in SPSS v15.0.1 for windows (SPSS, Inc.). The significance limit was set at 0.05. $P$ values for evaluation of differences in NQO1 and/ or $\mathrm{NF} \kappa \mathrm{B}$ expression in varying tumor characteristics were calculated using Pearson's chi-squared tests or Fisher's exact test (for $n<5$ ). All $P$ values are two sided. Log-rank tests were used to assess the statistical significance of differences between Kaplan-Meier curves for survival analyses among all patients. Univariate Cox's regression analyses were used to estimate relative risk in various subgroups. To ascertain the effect of differential NQO1protein expression on post-metastasis survival in the first series of patients, the beginning of follow-up time was set at date of diagnosed metastasis.

\section{Results}

We performed immunohistochemical analysis to study NQO1 and NF $\kappa$ B expression for association with tumor characteristics and survival in two series of breast cancer patients. NQO1 and $\mathrm{NF} \kappa \mathrm{B}$ staining results were obtained for $996(80 \%)$ and $1030(83 \%)$ tumors, respectively, from the first series of breast cancer patients. NQO1 expression and $\mathrm{NF} \kappa \mathrm{B}$ nuclear localization were seen in $83 \%$ and $11 \%$ of the tumors, respectively. There was no difference in the NQO1 expression or NF $\kappa$ B nuclear localization by family history background, therefore, all tumors were subsequently combined in the same analyses. From the second series of patients with metastatic disease, NQO1 and $\mathrm{NF} \kappa \mathrm{B}$ protein expression was obtained for 113 and 80 tumors, respectively. NQO1 was detected in $64 \%$ and $\mathrm{NF} \kappa \mathrm{B}$ nuclear localization in $15 \%$ of the analyzable tumors, respectively. Representative examples of NQO1 and p65 $\mathrm{NF} \kappa \mathrm{B}$-staining pattern for normal human breast tissue and breast carcinomas with positive and negative NQO1 or $\mathrm{NF} \kappa \mathrm{B}$ expression are shown in Fig. 1. The numbers of cases included in different analyses are shown in Supplementary Table 1.

Association between NQO1 protein expression and clinico-pathological data

There was an inverse correlation between NQO1 expression and $\mathrm{NF} \kappa \mathrm{B}$ nuclear localization/activation $(P=0.012)$. Furthermore, negative NQO1 was associated with ERnegativity $(P=0.011)$ but not with any other tumor characteristics. As expected, NQO1 staining correlated with the NQO1*2 homozygous variant genotype $(P<0.0001)$. NQO1*2 homozygous (TT, Ser/Ser) cases were always NQO1 protein negative, whereas tumors from 171/264 $(64 \%)$ of heterozygous patients and 541/573 (94\%) of wildtype homozygous patients were positive for NQO1
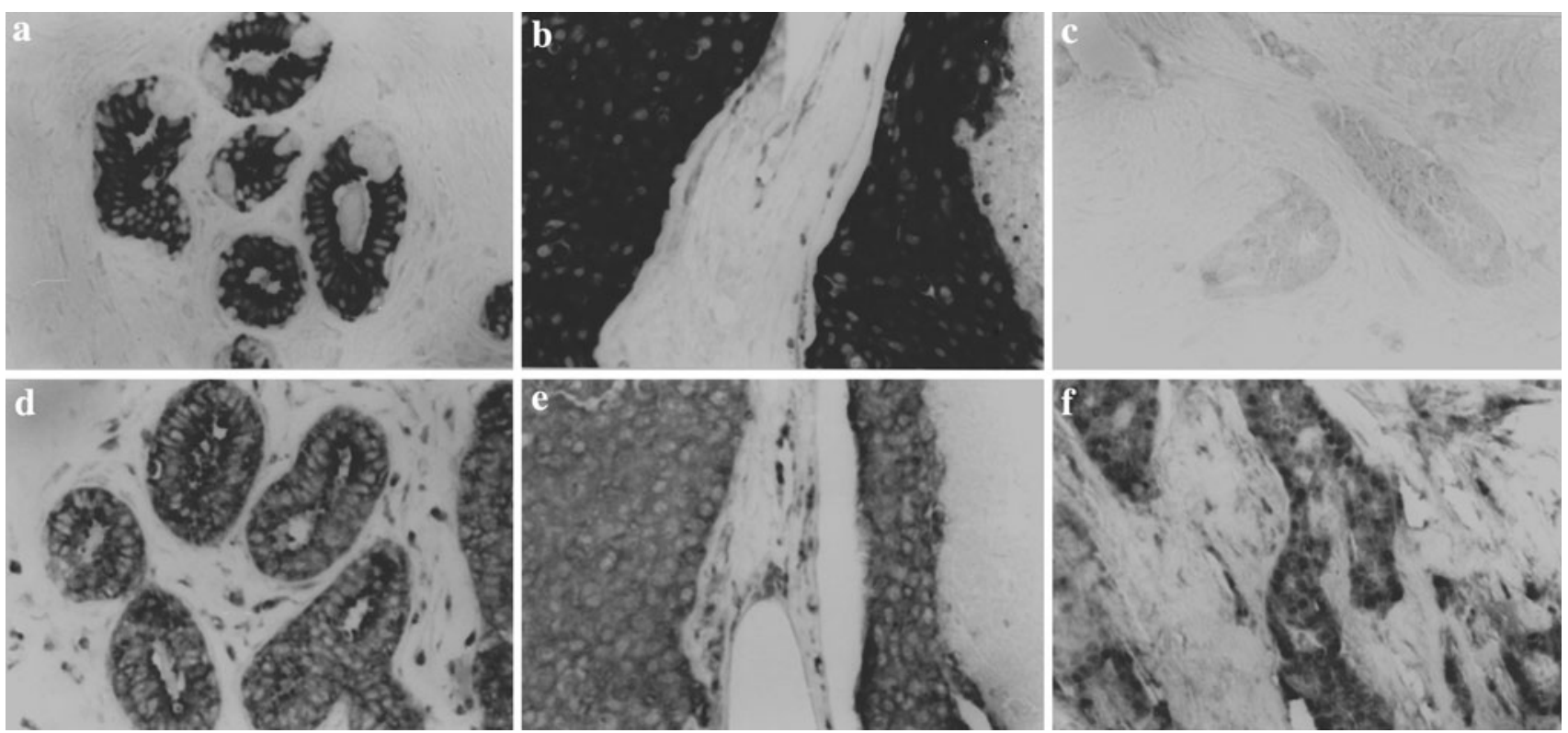

Fig. 1 Immunohistochemical detection of $\mathrm{NQO} 1$ and $\mathrm{NF} \kappa \mathrm{B}$ in human breast tumors. The images show NQO1-staining (top row) and $\mathrm{p} 65 \mathrm{NF} \kappa \mathrm{B}$-staining patterns (bottom row) for normal human breast tissue (a, d) and two breast carcinomas: one tumor with high abundance of NQO1 and cytoplasmic/inactive p65 NF $\kappa \mathrm{B}$ (b and e, respectively), the other tumor lacking NQO1 and showing nuclear p65 $\mathrm{NF} \kappa \mathrm{B}$-staining indicative of $\mathrm{NF} \kappa \mathrm{B}$ activation (c and $\mathbf{f}$, respectively) 
Table 1 Association of NQO1 protein expression with the clinicopathological features of the primary tumors in the first series of breast cancer patients with primary tumors

\begin{tabular}{|c|c|c|c|c|}
\hline & \multicolumn{3}{|l|}{$n(\%)$} & \multirow[t]{2}{*}{$P$} \\
\hline & Total $(n=996)$ & Positive exp. $(n=823)$ & Negative exp. $(n=173)$ & \\
\hline \multicolumn{5}{|l|}{ Patients group } \\
\hline Sporadic & $357(35.8)$ & $295(35.8)$ & $62(35.8)$ & 0.884 \\
\hline Large families & $362(36.3)$ & $295(35.8)$ & $67(38.7)$ & Sporadic vs. familial \\
\hline Small families & $277(27.8)$ & $233(28.3)$ & $44(25.4)$ & \\
\hline \multicolumn{5}{|l|}{ Tumor histology } \\
\hline Ductal carcinoma & $724(72.6)$ & $600(72.9)$ & $124(71.6)$ & 0.217 \\
\hline Lobular carcinoma & $165(16.5)$ & $130(15.7)$ & $35(20.2)$ & Ductal vs. lobular \\
\hline Medullary carcinoma & $13(1.3)$ & $9(1)$ & $4(2.3)$ & \\
\hline Other & $94(9.4)$ & $84(10.2)$ & $10(5.7)$ & \\
\hline \multicolumn{5}{|l|}{ Grade } \\
\hline 1 & $218(21.5)$ & $177(21.8)$ & $41(23.9)$ & $0.545,0.304 *$ \\
\hline 2 & $477(47.2)$ & $366(45.2)$ & $81(47.3)$ & 1 vs. 2 and 3 \\
\hline 3 & $315(31.1)$ & $266(32.8)$ & 49 (28.6) & \\
\hline NA & 16 & 14 & 2 & \\
\hline \multicolumn{5}{|l|}{$\mathrm{T}$} \\
\hline 1 & $564(57.4)$ & $468(57.4)$ & $96(57.1)$ & $0.932 *$ \\
\hline 2 & $352(35.8)$ & $289(35.5)$ & $63(37.5)$ & \\
\hline 3 & $34(3.4)$ & $33(4)$ & $1(0.5)$ & \\
\hline 4 & $32(3.2)$ & $24(2.9)$ & $8(4.7)$ & \\
\hline NA & 14 & 9 & 5 & \\
\hline \multicolumn{5}{|l|}{$\mathrm{N}$} \\
\hline Negative & $534(54.4)$ & $442(54.3)$ & $92(54.7)$ & 0.932 \\
\hline Positive & $447(45.5)$ & 371 (45.6) & $76(45.2)$ & \\
\hline NA & 15 & 10 & 5 & \\
\hline \multicolumn{5}{|l|}{ M } \\
\hline Negative & 954 (96.5) & 793 (96.9) & $161(94.7)$ & 0.163 \\
\hline Positive & $34(3.4)$ & $25(3)$ & $9(5.3)$ & \\
\hline NA & 8 & 5 & 3 & \\
\hline \multicolumn{5}{|l|}{ ER status } \\
\hline Negative & $201(21.3)$ & 155 (19.7) & $46(29.1)$ & 0.011 \\
\hline Positive & 742 (78.6) & $630(80.2)$ & $112(70.9)$ & \\
\hline NA & 53 & 38 & 15 & \\
\hline \multicolumn{5}{|l|}{ PgR status } \\
\hline Negative & $313(33.2)$ & $252(32.1)$ & $61(38.6)$ & 0.138 \\
\hline Positive & $628(66.7)$ & $531(67.8)$ & $97(61.3)$ & \\
\hline NA & 55 & 40 & 15 & \\
\hline \multicolumn{5}{|l|}{ p53 } \\
\hline Negative & $772(79.4)$ & $637(79.2)$ & $135(80.3)$ & 0.834 \\
\hline Positive & $200(20.5)$ & $167(20.7)$ & 33 (19.6) & \\
\hline NA & 24 & 19 & 5 & \\
\hline \multicolumn{5}{|l|}{ HER2 } \\
\hline Negative & $846(87.1)$ & $695(86.3)$ & 151 (90.9) & 0.126 \\
\hline Positive & 125 (12.8) & 110 (13.6) & $15(9)$ & \\
\hline NA & 25 & 18 & 7 & \\
\hline \multicolumn{5}{|l|}{ Ki-67 } \\
\hline Low & $660(66.7)$ & $551(67.3)$ & $109(63.7)$ & 0.373 \\
\hline
\end{tabular}


Table 1 continued

\begin{tabular}{|c|c|c|c|c|}
\hline & \multicolumn{3}{|l|}{$n(\%)$} & \multirow[t]{2}{*}{$P$} \\
\hline & Total $(n=996)$ & Positive exp. $(n=823)$ & Negative exp. $(n=173)$ & \\
\hline High & $329(33.2)$ & 267 (32.6) & $62(36.2)$ & \\
\hline NA & 7 & 5 & 2 & \\
\hline \multicolumn{5}{|l|}{ NQO1*2 } \\
\hline $\mathrm{CC}$ & $573(66.5)$ & $541(75.9)$ & $32(21.4)$ & $\ll 0.001, \ll 0.001 *$ \\
\hline $\mathrm{CT}$ & $264(30.6)$ & $171(24)$ & $93(62.4)$ & TT vs. CC and CT \\
\hline TT & $24(2.8)$ & $0(0)$ & $24(16.1)$ & \\
\hline NA & 135 & 111 & 24 & \\
\hline \multicolumn{5}{|l|}{$\mathrm{NF} \kappa \mathrm{B}$} \\
\hline Negative & $863(89.4)$ & $724(90.6)$ & $139(83.7)$ & 0.012 \\
\hline Positive & $102(10.5)$ & $75(9.3)$ & $27(16.2)$ & \\
\hline NA & 31 & 24 & 7 & \\
\hline
\end{tabular}

$T$ tumor size, $N$ nodal status, $M$ primary metastasis, $E R$ estrogen receptor, $P g R$ progesterone receptor

* Chi-squared test for trend

Table 2 Association of $\mathrm{NF} \kappa \mathrm{B}$ protein expression with the clinicopathological features of the tumors in the first series of breast cancer patients with primary tumors

\begin{tabular}{|c|c|c|c|c|}
\hline & \multicolumn{3}{|l|}{$n(\%)$} & \multirow[t]{2}{*}{$P$} \\
\hline & Total $(n=1030)$ & Negative exp. $(n=913)$ & Positive exp. $(n=117)$ & \\
\hline \multicolumn{5}{|l|}{ Patients group } \\
\hline Sporadic & $360(34.9)$ & $321(35.1)$ & $39(33.3)$ & \multirow[t]{3}{*}{0.696} \\
\hline Large families & $368(35.7)$ & $326(35.7)$ & $42(35.8)$ & \\
\hline Small families & $302(29.3)$ & $266(29.1)$ & $36(30.7)$ & \\
\hline \multicolumn{5}{|l|}{ Tumor histology } \\
\hline Ductal carcinoma & $745(72.3)$ & $658(72)$ & $87(74.3)$ & 0.017 \\
\hline Lobular carcinoma & $167(16.2)$ & $158(17.3)$ & $9(7.6)$ & \multirow[t]{3}{*}{ Ductal vs. lobular } \\
\hline Medullary carcinoma & $13(1.2)$ & $6(0.6)$ & $7(5.9)$ & \\
\hline Other & $105(10.1)$ & $91(9.9)$ & $14(11.9)$ & \\
\hline \multicolumn{5}{|l|}{ Grade } \\
\hline 1 & $232(22.8)$ & 194 (21.6) & $38(32.4)$ & \multirow{4}{*}{$\begin{array}{l}0.014,0.135^{*} \\
1 \text { vs. } 2 \text { and } 3\end{array}$} \\
\hline 2 & $462(45.5)$ & $420(46.8)$ & $42(35.8)$ & \\
\hline 3 & $320(31.5)$ & $283(31.5)$ & 37 (31.6) & \\
\hline NA & 16 & 16 & 0 & \\
\hline \multicolumn{5}{|l|}{$\mathrm{T}$} \\
\hline 1 & $585(57.6)$ & $517(57.5)$ & $68(58.1)$ & \multirow[t]{5}{*}{$0.930^{*}$} \\
\hline 2 & $366(36)$ & $324(36)$ & $42(35.8)$ & \\
\hline 3 & $32(3.1)$ & $29(3.2)$ & $3(2.5)$ & \\
\hline 4 & $32(3.1)$ & $28(3.1)$ & $4(3.4)$ & \\
\hline NA & 15 & 15 & 0 & \\
\hline \multicolumn{5}{|l|}{$\mathrm{N}$} \\
\hline Negative & $551(54.4)$ & $482(53.8)$ & $69(58.9)$ & \multirow[t]{3}{*}{0.324} \\
\hline Positive & $461(45.5)$ & $413(46.1)$ & $48(41)$ & \\
\hline NA & 18 & 18 & 0 & \\
\hline \multicolumn{5}{|l|}{ M } \\
\hline Negative & 989 (96.7) & 875 (96.6) & $114(97.4)$ & \multirow[t]{2}{*}{1.000} \\
\hline Positive & $33(3.2)$ & $30(3.3)$ & $3(2.6)$ & \\
\hline
\end{tabular}


Table 2 continued

\begin{tabular}{|c|c|c|c|c|}
\hline & \multicolumn{3}{|l|}{$n(\%)$} & \multirow[t]{2}{*}{$P$} \\
\hline & Total $(n=1030)$ & Negative exp. $(n=913)$ & Positive exp. $(n=117)$ & \\
\hline NA & 8 & 8 & 0 & \\
\hline \multicolumn{5}{|l|}{ ER status } \\
\hline Negative & $207(21.2)$ & $170(19.5)$ & $37(34.5)$ & 0.001 \\
\hline Positive & 768 (78.7) & $698(80.4)$ & $70(65.4)$ & \\
\hline NA & 55 & 45 & 10 & \\
\hline \multicolumn{5}{|l|}{ PgR status } \\
\hline Negative & $326(33.5)$ & $284(32.8)$ & $42(39.2)$ & 0.194 \\
\hline Positive & $646(66.4)$ & $581(67.1)$ & $65(60.7)$ & \\
\hline NA & 58 & 48 & 10 & \\
\hline \multicolumn{5}{|l|}{ p53 } \\
\hline Negative & 798 (79.7) & 709 (79.7) & $89(79.4)$ & 0.901 \\
\hline Positive & $203(20.2)$ & $180(20.2)$ & $23(20.5)$ & \\
\hline NA & 29 & 24 & 5 & \\
\hline \multicolumn{5}{|l|}{ HER2 } \\
\hline Negative & $865(86.5)$ & $762(86.1)$ & $103(88.7)$ & 0.563 \\
\hline Positive & $135(13.5)$ & $122(13.8)$ & $13(11.2)$ & \\
\hline NA & 30 & 29 & 1 & \\
\hline \multicolumn{5}{|l|}{ Ki-67 } \\
\hline Low & $688(67.2)$ & $606(66.8)$ & $82(70)$ & 0.531 \\
\hline High & $335(32.7)$ & $300(33.1)$ & $35(29.9)$ & \\
\hline NA & 7 & 7 & 0 & \\
\hline \multicolumn{5}{|l|}{ NQO1*2 } \\
\hline $\mathrm{CC}$ & $591(66.2)$ & $532(66.8)$ & $59(61.4)$ & 0.5 \\
\hline $\mathrm{CT}$ & $278(31.1)$ & $242(30.4)$ & $36(37.5)$ & TT vs. CC and CT \\
\hline TT & $23(2.5)$ & $22(2.7)$ & $1(1)$ & \\
\hline NA & 138 & 117 & 21 & \\
\hline \multicolumn{5}{|l|}{ NQO1 } \\
\hline Negative & $166(17.2)$ & $139(16.1)$ & $27(26.4)$ & 0.012 \\
\hline Positive & 799 (82.7) & $724(83.8)$ & $75(73.5)$ & \\
\hline NA & 65 & 50 & 15 & \\
\hline
\end{tabular}

$T$ tumor size, $N$ nodal status, $M$ primary metastasis, $E R$ estrogen receptor, $P g R$ progesterone receptor

* Chi-squared test for trend

immunostaining. Results of NQO1 protein expression in relation to tumor characteristics, $\mathrm{NF} \kappa \mathrm{B}$ activation, and NQO1*2 mutation status in the first breast cancer series are summarized in Table 1.

In the second series of 113 patients treated with chemotherapy after metastatic disease, no significant association was observed between clinico-pathological data and NQO1 protein expression (Supplementary Table 2).

Association between $\mathrm{NF} \kappa \mathrm{B}$ activation and clinicopathological data

Tumor characteristics according to $\mathrm{NF} \kappa \mathrm{B}$ immunohistochemistry in the first series are shown in Table 2. In addition to the inverse correlation with NQO1 expression, nuclear $\mathrm{NF} \kappa \mathrm{B}$ was associated with ductal histology $(P=0.017)$, ER-negativity $(P=0.001)$ and lower grade $(P=0.014)$.

In the second series of patients treated with chemotherapy for metastatic disease, no significant association to $\mathrm{NF} \kappa \mathrm{B}$ expression was detected (Supplementary Table 3 ).

Survival analyses

Survival analysis by NQO1 immunostaining did not show significant differences among all patients or in subgroups stratified by adjuvant chemotherapy treatment (Fig. 2; Table 3). In the chemotherapy trial group, there were no 

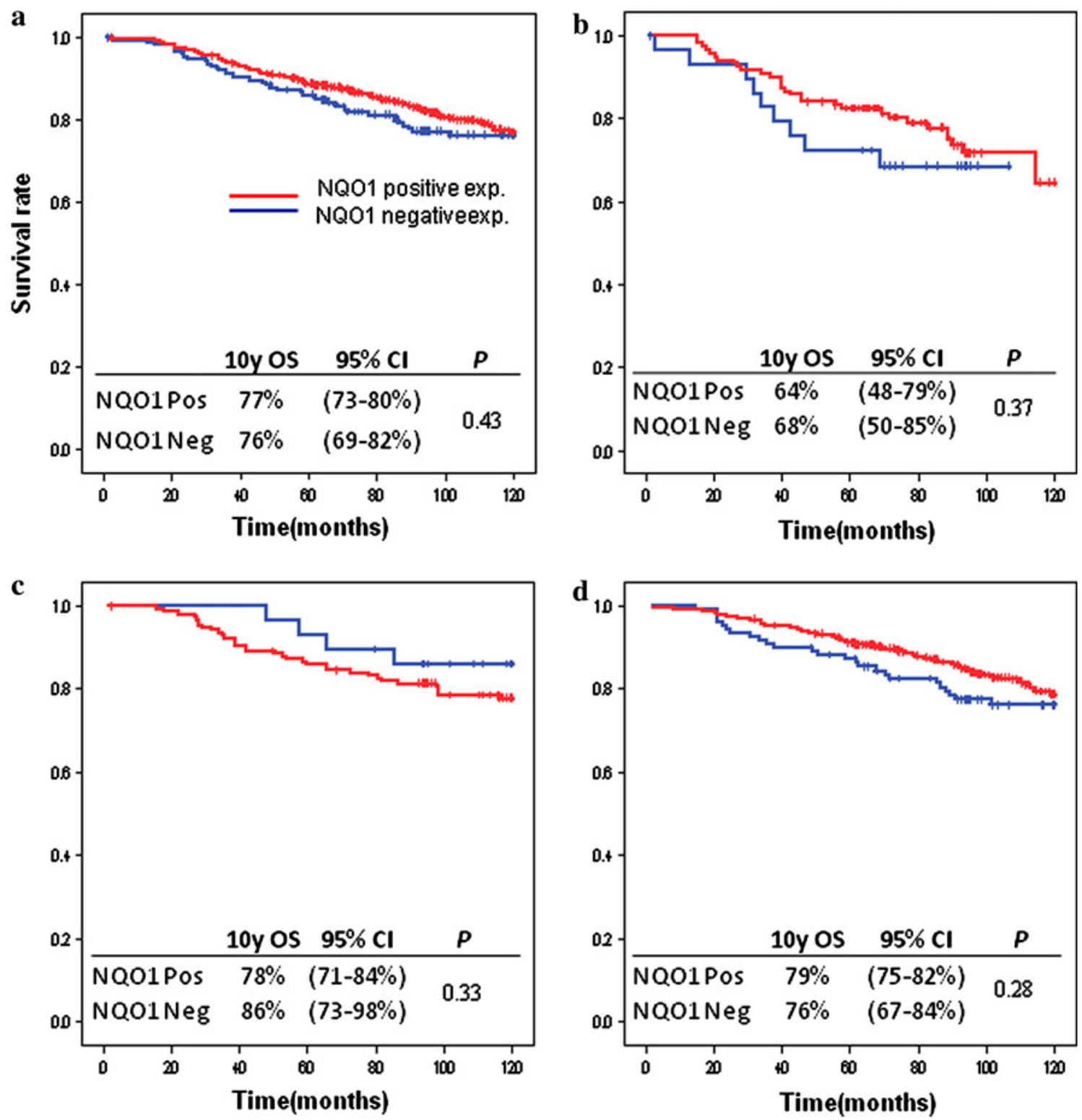

Fig. 2 Kaplan-Meier survival curves by NQO1 protein expression in the first series of patients with primary tumor. a 10-year overall survival after breast cancer diagnosis; 10-year overall survival among

individuals who received anthracycline treatment (b), non-anthracycline chemotherapy (c), no chemotherapy (d)

significant differences in treatment response, TTP or OS after first-line anthracycline treatment or after second-line docetaxel treatment (Supplementary Figure 1a-c; Table 4). However, patients with negative NQO1 expression had faster progression of the disease after second line methotrexate-fluorouracil treatment $(P=0.03$, HR $1.99,95 \% \mathrm{CI}$ 1.04-3.78, Supplementary Figure 1d; Table 4). NF $\kappa \mathrm{B}$ protein localization/activation in tumors did not show any significant association with patient survival (Fig. 3; Supplementary Figure 2).

Although not statistically significant, $\mathrm{NQO} 1$ and $\mathrm{NF} \kappa \mathrm{B}$ protein expression showed tendency for inverse survival after adjuvant anthracycline treatment (reduced survival for

patients with negative NQO1 or nuclear/activated $\mathrm{NF} \kappa \mathrm{B}$ ). Analogous non-significant survival tendency was found in both patient series for overall survival, and for survival from metastasis to death and for time to tumor progression after anthracycline treatment in the chemotherapy trial series (Figs. 2, 3; Tables 3, 4).

Microarray data analysis

In gene expression analysis, a total of 877 genes significantly correlated to $N Q O 1$ expression (293 positively and 584 negatively correlated) and 2,871 genes significantly correlated to $N F \kappa B 1$ expression (1,635 positively and 
Table 3 Univariate Cox's regression analysis by NQO1 and NF $\kappa$ B positive and negative protein expression for overall survival in the first series of breast cancer patients with primary tumors

\begin{tabular}{|c|c|c|c|c|c|}
\hline \multirow[t]{2}{*}{ Category } & \multicolumn{2}{|l|}{$n$ (death) } & \multirow[t]{2}{*}{$P$} & \multirow[t]{2}{*}{ HR } & \multirow[t]{2}{*}{$95 \% \mathrm{CI}$} \\
\hline & Positive exp. & Negative exp. & & & \\
\hline \multicolumn{6}{|c|}{ 10-year overall survival by NQO1 expression } \\
\hline All patients & $823(169)$ & $173(39)$ & 0.434 & 1.149 & $0.81-1.62$ \\
\hline Adj-AC treated & $120(30)$ & $29(9)$ & 0.377 & 1.401 & $0.66-2.96$ \\
\hline Adj_Non_AC & $157(34)$ & $29(4)$ & 0.339 & 0.603 & $0.21-1.70$ \\
\hline No_Adj_Chemo & $537(101)$ & $111(25)$ & 0.28 & 1.273 & $0.82-1.97$ \\
\hline \multicolumn{6}{|c|}{ Overall survival from metastases to death ( 5 years), by NQO1 expression } \\
\hline All patients & $146(102)$ & $32(23)$ & 0.3 & 1.271 & $0.80-2.00$ \\
\hline Adj_AC treated & $34(23)$ & $11(8)$ & 0.201 & 1.693 & $0.75-3.79$ \\
\hline Adj_Non_AC & $33(27)$ & $3(2)$ & 0.402 & 0.541 & $0.12-2.27$ \\
\hline No_Adj_Chemo & $79(52)$ & $18(13)$ & 0.241 & 1.44 & $0.78-2.65$ \\
\hline \multirow[t]{2}{*}{ Category } & \multicolumn{2}{|l|}{$n$ (death) } & $P$ & HR & $95 \% \mathrm{CI}$ \\
\hline & Negative exp. & Positive exp. & & & \\
\hline \multicolumn{6}{|c|}{ 10-year overall survival by $\mathrm{NF} \kappa \mathrm{B}$ expression } \\
\hline All patients & $913(197)$ & $117(23)$ & 0.464 & 0.851 & $0.55-1.31$ \\
\hline Adj_AC treated & $143(36)$ & $11(5)$ & 0.113 & 2.135 & $0.83-5.45$ \\
\hline Adj_Non_AC & $164(34)$ & $22(4)$ & 0.657 & 0.791 & $0.28-2.22$ \\
\hline No_Adj_Chemo & $594(122)$ & $82(13)$ & 0.255 & 0.717 & $0.40-1.27$ \\
\hline \multicolumn{6}{|c|}{ Overall survival from metastases to death ( 5 years), by $\mathrm{NF} \kappa \mathrm{B}$ expression } \\
\hline All patients & $168(122)$ & $16(10)$ & 0.57 & 0.83 & $0.43-1.58$ \\
\hline Adj_AC treated & $41(28)$ & $5(4)$ & 0.394 & 1.578 & $0.55-4.50$ \\
\hline Adj_Non_AC & $33(28)$ & $3(1)$ & 0.105 & 0.191 & $0.02-1.41$ \\
\hline No_Adj_Chemo & $94(66)$ & $8(5)$ & 0.959 & 0.976 & $0.39-2.42$ \\
\hline
\end{tabular}

Adj adjuvant, $A C$ anthracycline, Chemo chemotherapy

1,236 negatively) (Supplementary Figure 3, Supplementary Tables 4 and 5). Interestingly, among genes correlating negatively with $N Q O 1$ expression are TNF and 12 other genes related to the $T N F / N F \kappa B$ pathway as well as 4 genes related to Toll-like receptor (TLR) family. Altogether, 193 genes were significantly correlated both with $N Q O 1$ and $N F \kappa B 1$. Only the gene LIMA1 positively correlated both with $N Q O 1$ and $N F \kappa B 1$, while all the other genes had inverse correlations with $N Q O 1$ and $N F \kappa B 1$ : 59 genes correlated positively with $N Q O 1$ but negatively with $N F \kappa B 1$, while 133 genes correlated positively with $N F \kappa B 1$ but negatively with NQO1 (Supplementary Table 6). No genes showed concordant negative correlation both with $N Q O 1$ and $N F \kappa B 1$.

Opposite trends of the $N Q O 1$ and $N F \kappa B l$-correlated genes were also observed when considering expression of functional gene families. The gene families of the endoplasmic reticulum, oxidation/reduction, lipid biosynthesis, and steroid metabolism were significantly over-represented both among the NQO1-positively correlated and $N F \kappa B 1$ negatively correlated genes. Furthermore, biological themes associated with immune response, lymphocyte activation, Jak-STAT signaling, and apoptosis were significantly over-represented among the $N F \kappa B 1$-positively correlated and NQO1-negatively correlated genes (Fig. 4). Similar functional profiles were represented by the 193 NQO1- and NFKBI-commonly correlated genes (Supplementary Table 7).

\section{Discussion}

We have applied immunohistochemistry to study expression of $\mathrm{NQO} 1$ and nuclear localization of $\mathrm{NF} \kappa \mathrm{B}$ in two series of human breast tumors, with correlation to tumor characteristics and survival and tumor progression after adjuvant chemotherapy. We found an inverse correlation between NQO1 expression and $\mathrm{NF} \kappa \mathrm{B}$ nuclear localization, with correlation of NQO1 expression with ER-positive tumors and $\mathrm{NF} \kappa \mathrm{B}$ nuclear expression with ER-negative tumors. The gene expression profiling corroborated and extended the opposing effects of NQO1 and $\mathrm{NF} \kappa \mathrm{B}$ expression observed by the immunohistochemistry analysis. Interestingly, among genes which negatively correlated 
Table 4 Univariate Cox's regression analysis by NQO1 and NF $\kappa$ B protein expression for overall survival and time to tumor progression in the chemotherapy trial series with metastatic disease

\begin{tabular}{|c|c|c|c|c|c|}
\hline \multirow[t]{2}{*}{ Category } & \multicolumn{2}{|l|}{$n$ (event) } & \multirow[t]{2}{*}{$P$} & \multirow[t]{2}{*}{ HR } & \multirow[t]{2}{*}{$95 \% \mathrm{CI}$} \\
\hline & Positive exp. & Negative exp. & & & \\
\hline \multicolumn{6}{|c|}{ Overall survival and time to tumor progression by NQO1 expression } \\
\hline \multicolumn{6}{|c|}{ First line of treatment after metastasis } \\
\hline Anthracycline OS & $52(49)$ & $18(15)$ & 0.674 & 1.134 & $0.63-2.03$ \\
\hline Anthracycline TP & $52(52)$ & $18(18)$ & 0.348 & 1.299 & $0.75-2.24$ \\
\hline \multicolumn{6}{|c|}{ Second line of treatment after metastasis } \\
\hline Taxotere TP & $34(30)$ & $25(20)$ & 0.930 & 1.026 & $0.57-1.82$ \\
\hline M-F TP & $38(36)$ & 16 (16) & 0.035 & 1.992 & $1.04-3.78$ \\
\hline \multirow[t]{2}{*}{ Category } & \multicolumn{2}{|l|}{$n$ (event) } & $P$ & HR & $95 \% \mathrm{CI}$ \\
\hline & Negative exp. & Positive exp. & & & \\
\hline
\end{tabular}

Overall survival and time to tumor progression by $\mathrm{NF} \kappa \mathrm{B}$ expression

First line of treatment after metastasis

$\begin{array}{lrrrrr}\text { Anthracycline OS } & 48(43) & 7(7) & 0.194 & 1.728 & 0.75-3.94 \\ \text { Anthracycline TP } & 48(48) & 7(7) & 0.098 & 2.041 & 0.87-4.75 \\ \text { Second line of treatment after metastasis } & & & & \\ \text { Taxotere TP } & 37(32) & 7(6) & 0.583 & 1.285 & 0.52-3.13 \\ \text { M-F TP } & 31(29) & 5(5) & 0.169 & 1.993 & 0.74-5.32\end{array}$

Event is death for overall survival (OS) and tumor progression (TP) for other analyses

$M-F$ methotrexate-fluorourasil

with NQO1 are TNF, TNF-related genes and TLR-related genes. Both families promote $\mathrm{NF} \kappa \mathrm{B}$ nuclear import [49]. $N Q O 1$ gene expression correlated positively and $N F \kappa B$ gene expression negatively with genes implicated in cellular processes of oxidation/reduction, lipid biosynthesis, and steroid metabolism whereas the opposite correlation was found for biological themes associated with immune response, lymphocyte activation, Jak-STAT signaling and apoptosis, consistent with the published functions of NQO1 and $\mathrm{NF} \kappa \mathrm{B}$. The association between NQO1 and ER expression was not unexpected, given the role of NQO1 in estrogen metabolism and the fact that NQO1 is in part transcriptionally regulated by ER [50]. Indeed, our gene expression analysis shows that several genes involved in steroid metabolism are co-upregulated with $\mathrm{NQOI}$ in breast tumors. On the other hand, $\mathrm{NF} \kappa \mathrm{B}$ nuclear expression was more common in ER-negative tumors, consistent with previous data [51]. $\mathrm{ER}$ and $\mathrm{NF} \kappa \mathrm{B}$ reportedly mutually repress each other, in addition to which there may be functional differences in $\mathrm{NF} \kappa \mathrm{B}$ signalling depending on ER status [52]. These findings are thus anticipated in view of previous literature. In contrast, the inverse relationship between NQO1 protein expression and $\mathrm{NF} \kappa \mathrm{B}$ activation is a novel finding, and somewhat unexpected given that they have been shown to be commonly co-activated in both normal and malignant cells, even upregulating each other $[13,14,16,53]$. In melanoma, NQO1-mediated $\mathrm{NF} \kappa \mathrm{B}$ activation (through stabilization of BCL3) may drive cell cycle progression and proliferation [54]. This disparity between breast cancer and other malignancies and tissues might reflect ER signalling in breast cancer. Given the documented mutual repression between $\mathrm{ER}$ and $\mathrm{NF} \kappa \mathrm{B}$ and the ability of ER to induce NQO1, it may be that the effects of ER override the mutual regulation between NQO1 and $\mathrm{NF} \kappa \mathrm{B}$. Subgroup analyses of the association between $\mathrm{NQO} 1$ and $\mathrm{NF} \kappa \mathrm{B}$ in ER-positive and -negative cases separately (data not shown) unfortunately could not resolve this issue due to lack of statistical power especially in the smaller ER-negative group. In any case, it would appear that the NQO1-NF $\kappa \mathrm{B}$ interaction in breast cancer differs from several other tissues, and functional elucidation of the underlying causal mechanism could provide insight into the biology of breast cancer and, potentially, its treatment.

In our previous study, we have found a strong association of the variant genotype NQO1*2 with poor prognosis of breast cancer patients, especially those treated with anthracycline-based chemotherapy. The homozygous patients showed increased mortality and reduced median survival time also after detection of metastasis suggesting resistance to treatment of the metastatic cells [1]. Here, we evaluated whether also NQO1 protein expression associates with patient survival in general and in treatment subgroups specifically. The results from this study suggest that $\mathrm{NQO} 1$ expression, or $\mathrm{NF} \kappa \mathrm{B}$ activation, do not appear to be 

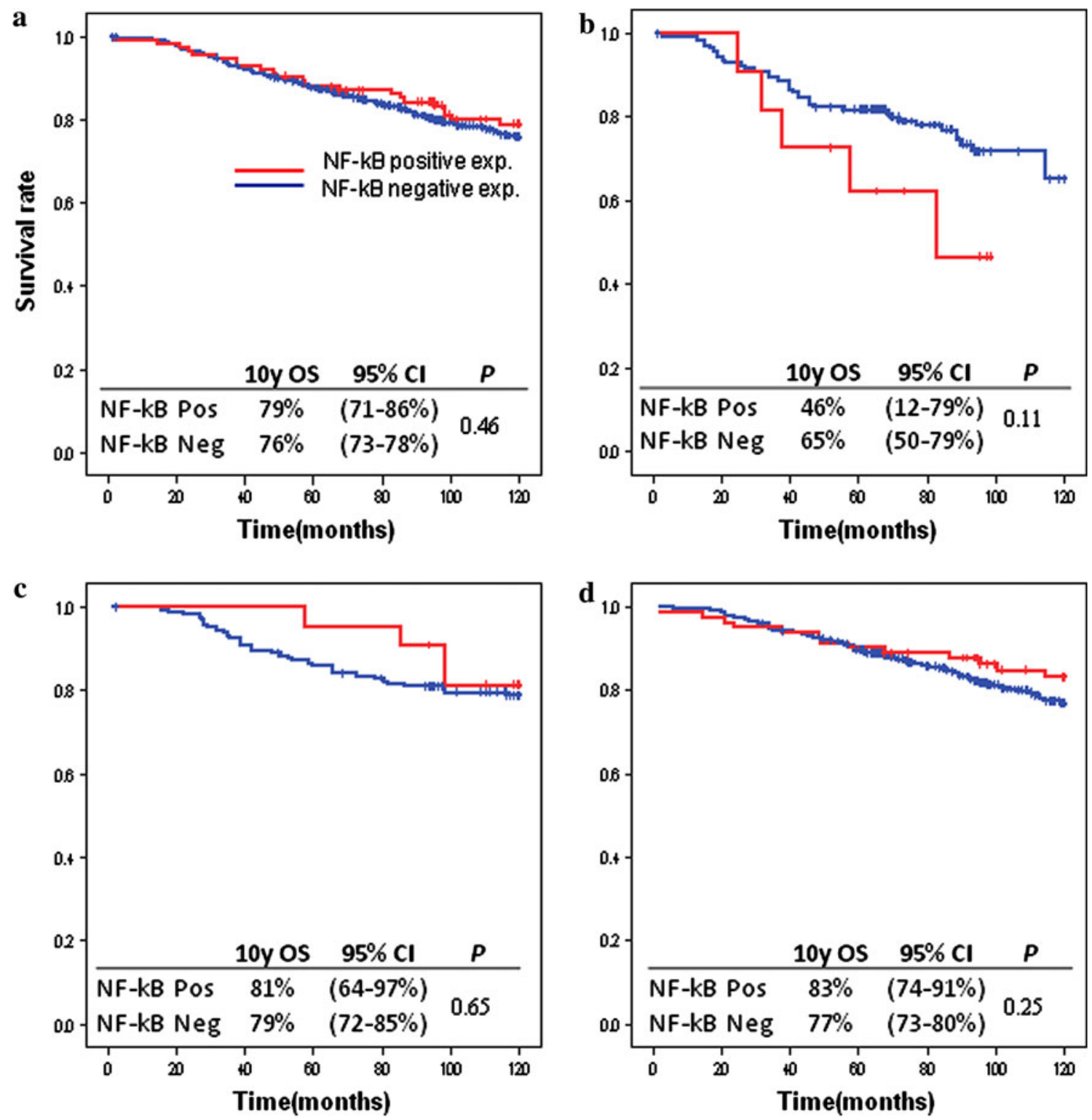

Fig. 3 Kaplan-Meier survival curves by $\mathrm{NF} \kappa \mathrm{B}$ protein expression in the first series of patients with primary tumor. a 10-year overall survival after breast cancer diagnosis; 10-year overall survival among

useful as prognostic or predictive markers in breast cancer. It is of note that while the NQO $1 * 2$ germ line genotype is strongly correlated with NQO1 protein expression, this correlation is not absolute. While all tumors from NQO1*2 homozygous patients stained negatively for NQO1, in line with previous reports $[4,55,56]$, lack of NQO1 expression was also observed in 93/264 (35\%) of the tumors from heterozygous carriers and 32/573 (5.5\%) of wild-type homozygotes. In other words, tumors with negative NQO1 immunostaining but wild-type or heterozygous $N Q O 1$ genotype are not directly analogous to NQO1*2 homozygous tumors. This could be due to a transient nature of NQO1 expression; lack of NQO1 immunostaining in a individuals who received anthracycline treatment (b), non-anthracycline chemotherapy (c), no chemotherapy (d)

given sample might not indicate that the cells are unable to express NQO1 in response to treatment, for example, but merely that the signalling event was not taking place when the sample was taken, or that the expression level is below detection threshold. Additionally, there does not appear to be strong selective pressure to lose the wild-type allele of NQO1 in breast tumors; in fact, the variant 609T allele was reportedly more commonly lost [57]. We observed no difference in genomic copy number of the region including NQO1 gene (16q22) between tumors from the normal wildtype, heterozygous, or homozygous NOQ1*2 variant carriers (data not shown) [58] further suggesting that the wildtype allele may be retained in the heterozygous carrier 


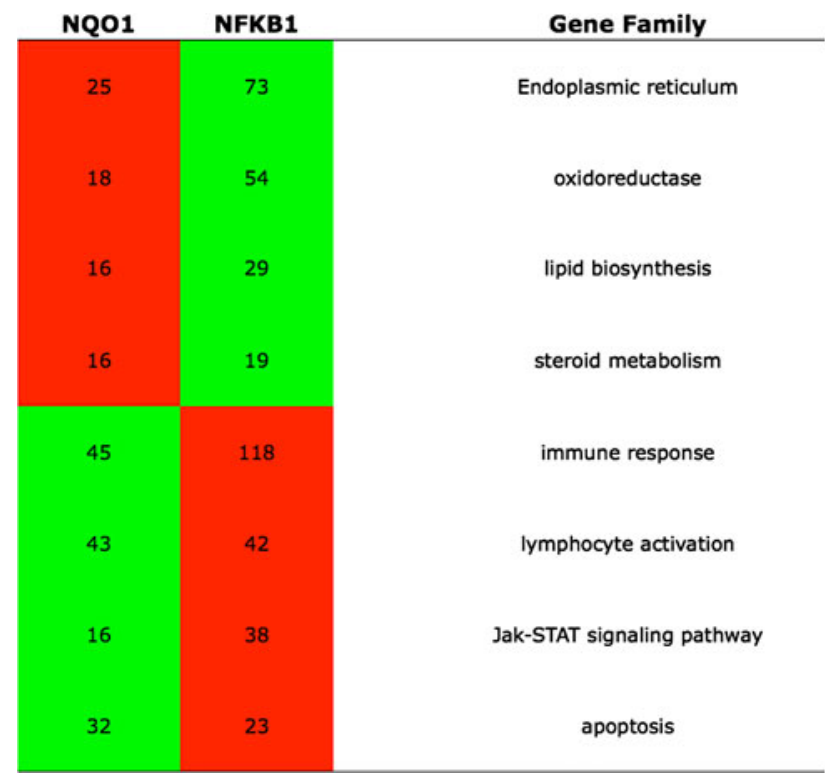

Fig. 4 Functional representation of genes correlating with NQO1 and $\mathrm{NF} \kappa \mathrm{B}$. The number of genes positively (red) and negatively correlated (green) and their functional annotation are shown

tumors, or not lost at least by genomic mechanisms. Given the lack of apparent LOH pressure, and the fact that NQO1 expression and $\mathrm{NF} \kappa \mathrm{B}$ activation were inversely correlated but not mutually exclusive, it is possible that the mutual upregulation between $\mathrm{NQO} 1$ and $\mathrm{NF} \kappa \mathrm{B}$, as documented in other studies, could also occur in some breast tumors. This could have separate impact on survival and treatment response, and might confound survival analyses stratified by NQO1 immunohistochemistry alone. Discovering such subgroups in a survival analysis would however require a very large sample set.

Despite the lack of support for NQO1 (or $\mathrm{NF} \kappa \mathrm{B}$ ) immunohistochemistry as prognostic or predictive markers, we observed that in the second series of patients treated with chemotherapy for metastatic disease, negative NQO1 immunostaining associated with faster disease progression after methotrexate-fluorouracil treatment following failure of anthracycline-based chemotherapy. This finding may suggest a pattern of differential association between NQO1 expression and response to various types of treatment, but lack of statistical power prevents a more granular analysis of the current material. We can speculate that NQO1*2 homozygotes are enriched in the anthracycline-resistant series, consistent with the higher frequency of tumors with negative NQO1 expression in this series, or that induction of NQO1 was lost by some other mechanism in advanced breast cancer due to treatment-related selective pressure. Very large studies are needed to further investigate association of NQO1 expression, preferably with available $\mathrm{NQO} 1 * 2$ genotype data, with the outcome of combined or sequential treatment with different chemotherapy agents.

Acknowledgments We thank Drs. Karl von Smitten and Kirsimari Aaltonen and nurses Hanna Jäntti and Irja Erkkilä for help in collecting the patient samples and data. The Finnish Cancer Registry is gratefully acknowledged for the cancer diagnostic and follow-up data. This study has been funded by the Helsinki University Central Hospital Research Fund, the Sigrid Juselius Foundation, the Finnish Cancer Society, the Academy of Finland (132473), the Danish Cancer Society, the Danish National Research Foundation, the Czech Ministry of Education (MSM6198959216), the Czech Ministry of Health (NS10282-3/2009) and the European Commission (projects InflaCare, CZ.1.05/2.1.00/01.0030, and DDResponse).

Conflict of Interest Licentia Ltd, representing Helsinki University Central Hospital and University of Helsinki, has filed PCT-patent application PCT/FI2007/050637 for NQO1, "Method for predicting the response to a therapy".

\section{References}

1. Fagerholm R, Hofstetter B, Tommiska J, Aaltonen K, Vrtel R, Syrjakoski $\mathrm{K}$ et al (2008) NAD(P)H:quinone oxidoreductase 1 NQO1*2 genotype (P187S) is a strong prognostic and predictive factor in breast cancer. Nat Genet 40:844-853

2. Traver RD, Siegel D, Beall HD, Phillips RM, Gibson NW, Franklin WA et al (1997) Characterization of a polymorphism in $\mathrm{NAD}(\mathrm{P}) \mathrm{H}$ :quinone oxidoreductase (DT-diaphorase). Br J Cancer 75:69-75

3. Siegel D, McGuinness SM, Winski SL, Ross D (1999) Genotypephenotype relationships in studies of a polymorphism in NAD(P)H:quinone oxidoreductase 1. Pharmacogenetics 9:113-121

4. Siegel D, Anwar A, Winski SL, Kepa JK, Zolman KL, Ross D (2001) Rapid polyubiquitination and proteasomal degradation of a mutant form of $\mathrm{NAD}(\mathrm{P}) \mathrm{H}$ :quinone oxidoreductase 1 . Mol Pharmacol 59:263-268

5. Siegel D, Ross D (2000) Immunodetection of NAD(P)H:quinone oxidoreductase 1 (NQO1) in human tissues. Free Radic Biol Med 29:246-253

6. Koudstaal J, Makkink B, Overdiep SH (1975) Enzyme histochemical pattern in human tumours II. Oxidoreductases in carcinoma of the colon and the breast. Eur J Cancer 11:111-115

7. Schlager JJ, Powis G (1990) Cytosolic NAD(P)H:(quinoneacceptor)oxidoreductase in human normal and tumor tissue: effects of cigarette smoking and alcohol. Int J Cancer 45:403-409

8. Talalay P, Dinkova-Kostova AT (2004) Role of nicotinamide quinone oxidoreductase 1 (NQO1) in protection against toxicity of electrophiles and reactive oxygen intermediates. Methods Enzymol 382:355-364

9. Adikesavan AK, Barrios R, Jaiswal AK (2007) In vivo role of $\mathrm{NAD}(\mathrm{P}) \mathrm{H}$ :quinone oxidoreductase 1 in metabolic activation of mitomycin $\mathrm{C}$ and bone marrow cytotoxicity. Cancer Res 67: 7966-7971

10. Asher G, Lotem J, Cohen B, Sachs L, Shaul Y (2001) Regulation of p53 stability and p53-dependent apoptosis by NADH quinone oxidoreductase 1. Proc Natl Acad Sci USA 98:1188-1193

11. Asher G, Lotem J, Kama R, Sachs L, Shaul Y (2002) NQO1 stabilizes p53 through a distinct pathway. Proc Natl Acad Sci USA 99:3099-3104

12. Gong X, Kole L, Iskander K, Jaiswal AK (2007) NRH:quinone oxidoreductase 2 and $\mathrm{NAD}(\mathrm{P}) \mathrm{H}$ :quinone oxidoreductase 1 protect tumor suppressor p53 against $20 \mathrm{~s}$ proteasomal degradation 
leading to stabilization and activation of p53. Cancer Res 67: 5380-5388

13. Ahn KS, Sethi G, Jain AK, Jaiswal AK, Aggarwal BB (2006) Genetic deletion of NAD(P)H:quinone oxidoreductase 1 abrogates activation of nuclear factor-kappaB, IkappaBalpha kinase, c-Jun N-terminal kinase, Akt, p38, and p44/42 mitogen-activated protein kinases and potentiates apoptosis. J Biol Chem 281: 19798-19808

14. Morgan MJ, Liu ZG (2011) Crosstalk of reactive oxygen species and NF-kappaB signaling. Cell Res 21:103-115

15. Perkins ND, Gilmore TD (2006) Good cop, bad cop: the different faces of NF-kappaB. Cell Death Differ 13:759-772

16. Iskander K, Li J, Han S, Zheng B, Jaiswal AK (2006) NQO1 and $\mathrm{NQO} 2$ regulation of humoral immunity and autoimmunity. J Biol Chem 281:30917-30924

17. Siemankowski LM, Morreale J, Butts BD, Briehl MM (2000) Increased tumor necrosis factor-alpha sensitivity of MCF-7 cells transfected with $\mathrm{NAD}(\mathrm{P}) \mathrm{H}$ :quinone reductase. Cancer Res 60: 3638-3644

18. Sethi G, Sung B, Aggarwal BB (2008) Nuclear factor-kappaB activation: from bench to bedside. Exp Biol Med 233:21-31

19. Mann AP, Verma A, Sethi G, Manavathi B, Wang H, Fok JY et al (2006) Overexpression of tissue transglutaminase leads to constitutive activation of nuclear factor-kappaB in cancer cells: delineation of a novel pathway. Cancer Res 66:8788-8795

20. Kim DW, Sovak MA, Zanieski G, Nonet G, Romieu-Mourez R, Lau AW et al (2000) Activation of NF-kappaB/Rel occurs early during neoplastic transformation of mammary cells. Carcinogenesis 21:871-879

21. Frasor J, Weaver A, Pradhan M, Dai Y, Miller LD, Lin CY et al (2009) Positive cross-talk between estrogen receptor and NFkappaB in breast cancer. Cancer Res 69:8918-8925

22. Bradbury CM, Markovina S, Wei SJ, Rene LM, Zoberi I, Horikoshi $\mathrm{N}$ et al (2001) Indomethacin-induced radiosensitization and inhibition of ionizing radiation-induced NF-kappaB activation in HeLa cells occur via a mechanism involving p38 MAP kinase. Cancer Res 61:7689-7696

23. Montagut C, Tusquets I, Ferrer B, Corominas JM, Bellosillo B, Campas $\mathrm{C}$ et al (2006) Activation of nuclear factor-kappa B is linked to resistance to neoadjuvant chemotherapy in breast cancer patients. Endocr Relat Cancer 13:607-616

24. Bottero V, Busuttil V, Loubat A, Magne N, Fischel JL, Milano G et al (2001) Activation of nuclear factor kappaB through the IKK complex by the topoisomerase poisons SN38 and doxorubicin: a brake to apoptosis in HeLa human carcinoma cells. Cancer Res 61:7785-7791

25. Ho WC, Dickson KM, Barker PA (2005) Nuclear factor-kappaB induced by doxorubicin is deficient in phosphorylation and acetylation and represses nuclear factor-kappaB-dependent transcription in cancer cells. Cancer Res 65:4273-4281

26. Syrjakoski K, Vahteristo P, Eerola H, Tamminen A, Kivinummi K, Sarantaus L et al (2000) Population-based study of BRCA1 and BRCA2 mutations in 1035 unselected Finnish breast cancer patients. J Natl Cancer Inst 92:1529-1531

27. Kilpivaara O, Bartkova J, Eerola H, Syrjakoski K, Vahteristo P, Lukas J et al (2005) Correlation of CHEK2 protein expression and c.1100delC mutation status with tumor characteristics among unselected breast cancer patients. Int J Cancer 113:575-580

28. Tommiska J, Eerola H, Heinonen M, Salonen L, Kaare M, Tallila $\mathrm{J}$ et al (2005) Breast cancer patients with p53 Pro72 homozygous genotype have a poorer survival. Clin Cancer Res 11:50985103

29. Vehmanen P, Friedman LS, Eerola H, McClure M, Ward B, Sarantaus L et al (1997) Low proportion of BRCA1 and BRCA2 mutations in Finnish breast cancer families: evidence for additional susceptibility genes. Hum Mol Genet 6:2309-2315
30. Vahteristo P, Bartkova J, Eerola H, Syrjakoski K, Ojala S, Kilpivaara $\mathrm{O}$ et al (2002) A CHEK2 genetic variant contributing to a substantial fraction of familial breast cancer. Am J Hum Genet 71:432-438

31. Vahteristo P, Eerola H, Tamminen A, Blomqvist C, Nevanlinna $\mathrm{H}$ (2001) A probability model for predicting BRCA1 and BRCA2 mutations in breast and breast-ovarian cancer families. $\mathrm{Br} \mathrm{J}$ Cancer 84:704-708

32. Elston CW, Ellis IO (1991) Pathological prognostic factors in breast cancer. I. The value of histological grade in breast cancer: experience from a large study with long-term follow-up. Histopathology 19:403-410

33. Tanner M, Gancberg D, Di Leo A, Larsimont D, Rouas G, Piccart MJ et al (2000) Chromogenic in situ hybridization: a practical alternative for fluorescence in situ hybridization to detect HER-2/ neu oncogene amplification in archival breast cancer samples. Am J Pathol 157:1467-1472

34. Lassus H, Leminen A, Vayrynen A, Cheng G, Gustafsson JA, Isola $\mathrm{J}$ et al (2004) ERBB2 amplification is superior to protein expression status in predicting patient outcome in serous ovarian carcinoma. Gynecol Oncol 92:31-39

35. Tommiska J, Bartkova J, Heinonen M, Hautala L, Kilpivaara O, Eerola $\mathrm{H}$ et al (2008) The DNA damage signalling kinase ATM is aberrantly reduced or lost in BRCA1/BRCA2-deficient and ER/PR/ ERBB2-triple-negative breast cancer. Oncogene 27:2501-2506

36. Ahlin C, Aaltonen K, Amini RM, Nevanlinna H, Fjallskog ML, Blomqvist C (2007) Ki67 and cyclin A as prognostic factors in early breast cancer. What are the optimal cut-off values? Histopathology 51:491-498

37. Sjostrom J, Blomqvist C, Mouridsen H, Pluzanska A, OttossonLonn S, Bengtsson NO et al (1999) Docetaxel compared with sequential methotrexate and 5-fluorouracil in patients with advanced breast cancer after anthracycline failure: a randomised phase III study with crossover on progression by the Scandinavian Breast Group. Eur J Cancer 35:1194-1201

38. Tynninen $\mathrm{O}$, Sjostrom J, von Boguslawski K, Bengtsson NO, Heikkila R, Malmstrom P et al (2002) Tumour microvessel density as predictor of chemotherapy response in breast cancer patients. Br J Cancer 86:1905-1908

39. Miller AB, Hoogstraten B, Staquet M, Winkler A (1981) Reporting results of cancer treatment. Cancer 47:207-214

40. McShane LM, Altman DG, Sauerbrei W, Taube SE, Gion M, Clark GM et al (2005) Reporting recommendations for tumor marker prognostic studies. J Clin Oncol 23:9067-9072

41. Bartkova J, Horejsi Z, Sehested M, Nesland JM, Rajpert-De Meyts E, Skakkebaek NE et al (2007) DNA damage response mediators MDC1 and 53BP1: constitutive activation and aberrant loss in breast and lung cancer, but not in testicular germ cell tumours. Oncogene 26:7414-7422

42. Lessard L, Begin LR, Gleave ME, Mes-Masson A-M, Saad F (2005) Nuclear localisation of nuclear factor-kappaB transcription factors in prostate cancer: an immunohistochemical study. $\mathrm{Br}$ J Cancer 93:1019-1023

43. Gentleman RC, Carey VJ, Bates DM, Bolstad B, Dettling M, Dudoit S et al (2004) Bioconductor: open software development for computational biology and bioinformatics. Genome Biol 5:R80

44. Du P, Kibbe WA, Lin SM (2008) lumi: a pipeline for processing Illumina microarray. Bioinformatics 24:1547-1548

45. Bolstad BM, Irizarry RA, Astrand M, Speed TP (2003) A comparison of normalization methods for high density oligonucleotide array data based on variance and bias. Bioinformatics 19: 185-193

46. Tatusova $\mathrm{T}$ (2010) Genomic databases and resources at the National Center for Biotechnology Information. Methods Mol Biol 609:17-44 
47. Benjamini Y, Hochberg Y (1995) Controlling the false discovery rate: a practical and powerful approach to multiple testing. J Roy Stat Soc 57:289-300

48. Huang da W, Sherman BT, Lempicki RA (2009) Systematic and integrative analysis of large gene lists using DAVID bioinformatics resources. Nat Protoc 4:44-57

49. Verstrepen L, Bekaert T, Chau TL, Tavernier J, Chariot A, Beyaert R (2008) TLR-4, IL-1R and TNF-R signaling to NF-kappaB: variations on a common theme. Cell Mol Life Sci 65:2964-2978

50. Carroll JS, Meyer CA, Song J, Li W, Geistlinger TR, Eeckhoute J et al (2006) Genome-wide analysis of estrogen receptor binding sites. Nat Genet 38:1289-1297

51. Jones RL, Rojo F, A'hern R, Villena N, Salter J, Corominas JM, et al. (2010) Nuclear NF-\{kappa\}B/p65 expression and response to neoadjuvant chemotherapy in breast cancer. J Clin Pathol 64:130-135

52. Gionet N, Jansson D, Mader S, Pratt MA (2009) NF-kappaB and estrogen receptor alpha interactions: differential function in estrogen receptor-negative and -positive hormone-independent breast cancer cells. J Cell Biochem 107:448-459

53. Cheng Y, Li J, Martinka M, Li G (2010) The expression of $\mathrm{NAD}(\mathrm{P}) \mathrm{H}$ :quinone oxidoreductase 1 is increased along with NF-kappaB p105/p50 in human cutaneous melanomas. Oncol Rep 23:973-979
54. Garate M, Wani AA, Li G (2010) The NAD(P)H:quinone oxidoreductase 1 induces cell cycle progression and proliferation of melanoma cells. Free Radic Biol Med 48:1601-1609

55. Hubackova M, Vaclavikova R, Mrhalova M, Kubackova K, Kodet R, Gut I et al (2009) NAD(P)H:quinone oxidoreductase 1 Pro187Ser polymorphism and expression do not cosegregate with clinico-pathological characteristics of human mammary tumors. Pharmacogenet Genomics 19:505-512

56. Sarbia M, Bitzer M, Siegel D, Ross D, Schulz WA, Zotz RB et al (2003) Association between NAD(P)H:quinone oxidoreductase 1 (NQ01) inactivating C609T polymorphism and adenocarcinoma of the upper gastrointestinal tract. Int J Cancer 107:381-386

57. Cleton-Jansen AM, van Eijk R, Lombaerts M, Schmidt MK, Van't Veer LJ, Philippo K et al (2008) ATBF1 and NQO1 as candidate targets for allelic loss at chromosome arm 16q in breast cancer: absence of somatic ATBF1 mutations and no role for the C609T NQO1 polymorphism. BMC Cancer 8:105

58. Jonsson G, Staaf J, Vallon-Christersson J, Ringner M, Holm K, Hegardt C et al (2010) Genomic subtypes of breast cancer identified by array-comparative genomic hybridization display distinct molecular and clinical characteristics. Breast Cancer Res $12: \mathrm{R} 42$ 